myofibrils, that is, with no firm links of adherence to the latter. At other times certain regions of the myofibrils could bccome firmly attached to the sarcolemma. This dynamic view of the sarcolemma forming specialized links with myofibrillar regions could help in assessing its function during the contractile process of living muscle. It could help in understanding how muscle cells act in concert, while it could provide a basis for explaining why regions of the sarcolemma, under electrical stimulation, lead to differing responses in the contractile pattern of the myofibrils ${ }^{4}$. Perhaps most important is the possibility that it could provide a basis for the transmission of the contractile force of the myofibrils to the endomysial and perimysial connective tissue and ultimately to the muscle tendon. Majority opinion at present ${ }^{5}$ holds that there is no permanent structural continuity between sarcolemma and the myofibrils, because of the ease with which the sarcolemma may be induced to separate from the muscle substance by a wide variety of methods. What is sug. gested here is that, depending on the contractile state of myofibrils, a definite pattern of adhesion may occur between the sarcolemma and the myofibrils; further, that this adhesion may be involved not only in transmitting electrical impulses to the myofibrils, but also in transmitting the contractile force of the latter to the connective tissue structures.

Apart from its possible significance in physiological states of muscle, the sarcolemma-basement membrane may play an important part in post-mortem effects, that is, it may determine the rate of release of sarcoplasm and other materials from the muscle cells. Once the integrity of this membrane system has been impaired, it is likely that the endomysial connective tissue will then be concerned in determining the rate of drip or exudation from meat. Work at present in progress in these laboratories, to be reported in full elsewhere, suggests that the drip characteristics of meat depend markedly on whether the tissue is in the pre- or post-rigor condition and therefore on the state of the sarcolemma-basement membrane system.

We wish to acknowledge the support given by the Pig Industries Development Authority during these investiga. tions.

$$
\begin{aligned}
& \text { R. REED } \\
& \text { T. W. Houston } \\
& \text { P. M. TODD }
\end{aligned}
$$

Procter Department of Food and Leather Science, University of Leeds.

${ }^{1}$ Bennett, H. S., in The Structure and Function of Muscle, edit. by Bourne, G. H. (Academic Press, London, 1960).

${ }^{2}$ Reed, R., and Rudall, K. M., Biochim. Biophys. Acta, 2,7 (1948).

${ }^{3}$ Reed, R., and Rudall, K. M., Biochim. Biophys. Acta, 2,19 (1948).

${ }^{4}$ Huxley, A. F., and Taylor, R. E., J. Physiol., London, 130, 49 (1955).

-Walls, E. W., in The Structure and Function of Muscle, edit. by Bourne, G. H. (Academic Press, London, 1960).

\section{Effect of Peroxides on the Hydration Elongation of Rat Tail Tendon}

Ir has been shown that physico-chemical changes occur when connective tissue is treated with water that has been subjected to ultrasonic vibrations ${ }^{1}$. The suggestion has been advanced that chemically active substances are formed through the ionization of the water in such ultrasonic fields, and that peroxides are probably involved ${ }^{2}$.

Collagen fibres were used to investigate the proposed action of these substances. The fibres were obtained from rat tails (Wistar males, 3 months old) according to the method described by Elden ${ }^{8}$. Before each experiment was carried out, the fibres were dehydrated until a constant ratio of weight and length was achieved. The individual fibres were fixed lengthwise to the bottom of a $2 \mathrm{ml}$. 'Perspex' cell. The fibres wore measured microscopically and divided into three classes according to their diameter. The fixed fibres were set to the mark of a measuring eyepiece (the magnification was $\times 150$ ). The time was measured from the moment the solution was injected into the cell until the fibre jerked off the setting mark. This time interval served as a measure of the beginning of longitudinal elongation of the fibre due to hydration. Deionized water $(p \mathbf{H} 6 \cdot 6-6 \cdot 8)$ was used as the control solution, while hydrogen peroxide in deionized water at concentrations of $1,0 \cdot 1,0 \cdot 01$ and $0 \cdot 001$ por cent were used as experimental solutions. The concentration of peroxide was controlled by polarography

\begin{tabular}{|c|c|c|c|c|}
\hline & & & & \\
\hline & Control & $21.40 \stackrel{I}{ \pm} 1.58$ & $27.35^{\text {II }} \pm 1.97$ & $\underset{29 \cdot 70 \pm 1 \cdot 8}{\text { III }}$ \\
\hline $\begin{array}{l}\text { Percentage } \\
\text { of hydro- }\end{array}$ & $\begin{array}{l}0 \cdot 001 \\
0 \cdot 01 \\
0 \cdot 1\end{array}$ & $\begin{array}{r}8.95 \pm 0.50 \\
11.90 \pm 0.27 \\
13.50 \pm 0.71\end{array}$ & $\begin{array}{l}15.40 \pm 1.34 \\
13.50 \pm 0.64 \\
16.80 \pm 0.78\end{array}$ & $\begin{array}{l}20 \cdot 60 \pm 1 \cdot 8 \\
16 \cdot 30 \pm 0 \cdot 5 \\
20 \cdot 10 \pm 1 \cdot 1\end{array}$ \\
\hline oxide & $1 \cdot 0$ & $17.40 \pm 0.75$ & $23.40 \pm 2 \cdot 33^{*}$ & $23 \cdot 61 \pm 1$. \\
\hline
\end{tabular}
and the solutions were applied at a temperature of $21^{\circ} \mathrm{C}$. Table 1 presents the results of our experiments.

Mean time in seconds ( $\pm S . E$. .) of the onset of hydration-elongation of the three classes of collagen fibres of various diameter (I, 84-126 ; II $126-168 \mu$; III, $168-210 \mu$ ) under the influence of a control solution and various concentrations of hydrogen peroxide. In each group ten fibres were measured. With the exccption of one value $(*)$, all the experimental (- peroxide) values are significantly different from the control.

In Table 1 it can be seen that the peroxides influenced the onset of elongation, but that the extent to which they were effective depended on the concentration and diameter of the rat-tail tendon. The beginning of elongation was accelerated most in the fibres with smallest diameter and with the lowest concentration of hydrogen peroxide in the solution; however, in the fibres with larger diameters the maximum acceleration is shifted towards higher concentrations.

These results can be explained in the following way. Either the chemically active substances, formed through the decomposition of hydrogen peroxide, facilitate the penetration of water through the membrane enveloping the rat-tail tendon ${ }^{4}$, or they directly influence the hydration rate of the collagen proteins ${ }^{5}$. Of special interest is the decrease in the efficiency of peroxides with increasing concentrations, which is analogous to the haemolytic effect of peroxides ${ }^{6}$; however, for the time being, this effect must remain unexplained.

\section{J. Pospištuova}

Department for Medical Physics, Medical Faculty, Purkyně University,

Brno, Czechoslovakia.

1 Pospísilová, J., Experientia, 20, 120 (1964).

2 Hughes, D. E., and Nyborg, W. L., Science, 138, 108 (1962).

Filden, H. R., Nature, 188, 1681 (1959).

'Kwon, D. S., Mason, P., and Rigby, B. J., Nature, 201, 159 (1964).

5 Day, T. D., Nature, 162, 152 (1948).

-György, P., and Rose, C., Ann. N.Y. Acad. Sci., 52, 231 (1949).

\section{A Re-investigation of the Effects of 'Nilevar' on the Right Gonad of the Pullet}

IN the female chicken, as in most female birds, only the left gonad develops into a functional ovary. Surgical removal of this left ovary is followed by hypertrophy of the right rudimentary gonad, indicating that the ovary exerts an inhibitory effect on the development of the right gonad (see refs. 1 and 2 for reviews). Kornfeld ${ }^{3}$ and Taber et al..$^{4,5}$ demonstrated that physiological amounts of oestrogen inhibit the hypertrophy of the rudimentary gonad following sinistral ovariectomy. This inhibition does not appear to be due to suppression of pituitary gonadotrophins.

Kornfeld ${ }^{6}$ administered 'Nilevar' (17 $\alpha$-ethyl-19-nortestosterone), a synthetic progestational compound and a reported "anti-oestrogen", to intact pullets. He reported a four-fold increase in the weights of the rudimentary 